\title{
Análise comparativa da anatomia foliar de Melastomataceae em ambiente de vereda e cerrado sensu stricto $^{1}$
}

\author{
Nádia Sílvia Somavilla² e Dalva Graciano-Ribeiro ${ }^{2,3}$
}

Recebido em 20/01/2011. Aceito em 9/08/2011

\begin{abstract}
RESUMO
(Análise comparativa da anatomia foliar de Melastomataceae em ambiente de vereda e cerrado sensu stricto). Este trabalho descreve a anatomia das lâminas foliares de três espécies de Melastomataceae, Lavoisiera bergii Cogn., Macairea radula (Bonpl.) DC. e Trembleya parviflora (D. Don) Cogn. que estão colonizando a zona alagável e aberta de fundo de vereda e de M. radula e T. parviflora que ocorrem no cerrado sensu stricto da Estação Ecológica de Águas Emendadas, Planaltina/DF. Os dados estruturais mostrados pelas três espécies indicam escleromorfia com características particulares a cada uma delas, como projeções nas células epidérmicas de L. bergii, diferentes tipos e localização de emergências formadas por esclereídes em $L$. bergii e $M$. radula, e evaginações na epiderme de T. parviflora. A caracterização anatômica das folhas de M. radula e T. parviflora não difere entre os ambientes. No entanto, as lâminas foliares dos indivíduos encontrados na vereda apresentaram plasticidade com valores significativamente $(\mathrm{P} \leq 0,05)$ maiores para espessura do mesofilo e do parênquima para massa foliar e massa foliar específica em relação aos indivíduos do cerrado sensu stricto. Esta relação é inversa para valores de área foliar específica. A capacidade de apresentar plasticidade estrutural, juntamente com a escleromorfia, pode ter sido relevante para o comportamento invasivo destas espécies na zona de fundo da vereda como destacado na discussão. Além deste ponto, o texto também apresenta uma breve discussão sobre outros aspectos relacionados à importância de estruturas anatômicas na taxonomia e ecologia destas espécies.
\end{abstract}

Palavras-chave: emergências foliares, escleromorfismo, plasticidade

\begin{abstract}
(Comparative analysis of Melastomataceae leaf anatomy in palm swamp and cerrado sensu stricto environments). This study describes the anatomy of the leaf blade of three species of Melastomataceae, Lavoisiera bergii Cogn., Macairea radula (Bonpl.) DC. and Trembleya parviflora (D. Don) Cogn., which colonize the flooded and open areas of a lower zone of palm swamp, and the M. radula and T. parviflora, which occur in cerrado sensu stricto, of the Estação Ecológica de Águas Emendadas, Planaltina, DF. Structural data of the three species indicate sclerophylly with particular characteristics to each of them, such as projections on epidermal cells of $L$. bergii, different types and position of emergencies in L. bergii and M. radula and the protrusion in the epidermis of T. parviflora. Anatomical characterization of the leaves of M. radula and T. parviflora did not differ between environments. However, the leaf blades of individuals of M. radula and T. parviflora found in the palm swamp showed plasticity in relation to individuals from the cerrado sensu stricto. Significantly higher values $(\mathrm{P} \leq 0.05)$ for the thickness of the mesophyll and chlorophyll parenchyma, leaf mass and specific leaf mass were found in the palm swamp. This relationship is reversed for values of specific leaf area. The ability to provide structural plasticity together with sclerophylly may be relevant to the invasive behavior of these species in the palm swamp as emphasized in the discussion. Moreover, this work also presents a brief discussion of other aspects related to the importance of anatomical structures in the taxonomy and ecology of these species.
\end{abstract}

Key words: leaf emergences, sclerophylly, plasticity

\footnotetext{
Parte da tese de Doutorado da primeira Autora

2 Universidade de Brasília, Instituto de Ciências Biológicas, Departamento de Botânica, Laboratório de Anatomia Vegetal, Brasília, DF, Brasil

3 Autor para correspondência: graciano@unb.br
} 


\section{Introdução}

As folhas são os órgãos vegetativos com maior variedade de características morfológicas e anatômicas e, de forma geral, expressam as condições ambientais de seu habitat (Esau 1976; Fahn 1982; Hickey \& King 2000). Além disso, apresentam plasticidade, mostrando variações destas características em relação a diferentes intensidades luminosas (Strauss-Debenedetti \& Berlyn 1994; Lindorf 1997; Baruch et al. 2000; Jaakola et al. 2004; Justo et al. 2005; Rossatto \& Kolb 2010), disponibilidade de nutrientes no solo (Feller 1996), regime hídrico (Rôças et al. 1997; Wang et al. 2007) e herbivoria (Turner 1994; Karban \& Baldwin 1997; Ribeiro et al. 2010).

$\mathrm{Na}$ maioria das espécies, a maneira como as folhas estão estruturadas anatomicamente tende a maximizar os processos de produção de alimento e energia, em especial a captação de radiação fotossinteticamente ativa, como também minimizar a perda de água por evapotranspiração e os danos da radiação excessiva (Brown \& Hattersley 1989; Larcher 2000; Mediavilla et al. 2001; Taiz \& Zeiger 2009).

A análise anatômica das folhas de espécies do Cerrado tem revelado uma convergência para o escleromorfismo (Paviani 1978; Bieras \& Sajo 2004; Rio et al. 2005; Bieras \& Sajo 2009; Rossatto \& Kolb 2010). A escleromorfia é mais frequentemente atribuída ao oligotrofismo, pela deficiência de nitrogênio e fósforo (Sobrado \& Medina 1980; Medina et al. 1990; Feller 1996; Gonçalves-Alvim et al. 2004; Read et al. 2006) e intensidade luminosa (Groom \& Lamont 1997, Marques et al. 1999).

O emprego de estudos anatômicos foliares tem-se revelado promissor no âmbito ecológico. No entanto, a conjugação de caracteres anatômicos que permite distinguir indivíduos inclusive em nível de espécie já é uma prática consagrada nos estudos taxonômicos como, por exemplo, nos trabalhos de Anderson \& Creech (1975), Prychid \& Rudall (1999), Alves et al. (2002), Bieras \& Sajo (2004), Kocsis et al. (2004) e Gomes et al. (2009) entre outros, sendo importante fonte de caracteres para análises filogenéticas.

Em Melastomataceae, alguns trabalhos ressaltam a importância de características anatômicas foliares usadas para identificar e diferenciar gêneros e espécies, tais como a diversidade de tricomas (Wurdack 1986; Mentink \& Baas 1992; Guimarães \& Martins 1997; Milanez 2007), de cristais e de estômatos (Baas 1981) e de esclereídes (Rao et al. 1980). Além disso, estudos relacionados à plasticidade anatômica mostram que espécies desta família possuem capacidade de adaptação a alterações nas condições ambientais (Gardoni et al. 2007; Boeger et al. 2008; Ribeiro et al. 2010).

Os trabalhos que descrevem a anatomia foliar de Melastomataceae, no Cerrado, são mais restritos a espécies que ocorrem em solos drenados ou em áreas úmidas de margem de mata de galeria (Reis et al. 2004; Reis et al. 2005; Milanez 2007). Não há estudos em ambientes de veredas, apesar desta família ser bem representativa em levantamentos fitossociológicos nesta fitofisionomia (Araújo et al. 2002; Guimarães et al. 2002; Meirelles et al. 2002; Oliveira 2005; Barbosa-Silva 2007).

Veredas são caracterizadas pela presença da palmeira arbórea Mauritia flexuosa (buriti) emergente, sem formar dossel, em meio a agrupamentos herbáceo-arbustivos e, geralmente, ocupam os vales pouco íngremes ou áreas planas, acompanhando linhas de drenagem mal definidas (Ribeiro \& Walter 2008). Os solos encontrados neste tipo de formação vegetacional são os hidromórficos mal drenados ou muito mal drenados (Reatto et al. 1998; Amaral 2002; Araújo et al. 2002; Guimarães et al. 2002). Araújo et al. (2002) delimita três zonas em veredas, de acordo com o relevo e altura do lençol freático, e as identifica como zonas de fundo (com solo saturado), meio (com solo medianamente úmido) e bordo (com solo mais seco).

$\mathrm{Na}$ Vereda Grande da Estação Ecológica de Águas Emendadas, Planaltina/DF, a colonização da zona de fundo por Lavoisiera bergii Cogn., Macairea radula (Bonpl.) DC. e Trembleya parviflora (D. Don) Cogn. (Meirelles et al. 2004; Barbosa-Silva 2007) vem sendo considerada como um comportamento invasivo, em resposta a alterações na altura do lençol freático (Silva Júnior \& Felfili 1996; Eiten 2001; Meirelles et al. 2004). Nesta zona da vereda, indivíduos das três espécies formam o estrato subarbustivo e a parte aérea fica exposta à incidência solar direta e sujeitas à dessecação. M. radula e T. parviflora também ocorrem no cerrado sensu stricto que margeia a vereda e, neste ambiente, fazem parte do estrato arbustivo e arbóreo, sendo sombreadas em determinados períodos do dia.

À partir destas considerações, este estudo tem como objetivo descrever a anatomia foliar de Lavoisiera bergii, Macairea radula e Trembleya parviflora com a finalidade de contribuir para o conhecimento anatômico dessa família em áreas úmidas, de identificar caracteres estruturais que podem estar associados ao estabelecimento destas plantas na zona de fundo da vereda e de verificar a possível plasticidade anatômica nas folhas dos indivíduos de Macairea radula e Trembleya parviflora que ocorrem nesta zona da vereda e no cerrado sensu stricto.

\section{Material e métodos}

\section{Local de coleta}

Neste estudo foram analisadas folhas completamente expandidas do $3^{\circ}$ ao $6^{\circ}$ nó de $L$. bergii, M. radula e T. parviflora coletadas na zona de fundo da vereda e de $M$. radula e $T$. parviflora coletadas no cerrado sensu stricto adjacente. Estas áreas de coleta estão localizadas na Estação Ecológica de Águas Emendadas, uma Unidade de Conservação pertencente à cidade de Planaltina (entre 15³2' e 15⒊'S e entre 47³3’ e 47³7’W), Distrito Federal, Brasil. O clima nesta região é tropical tipo Aw pela classificação de Köppen, ou seja, clima de savana com temperatura superior a $18^{\circ} \mathrm{C}$ no 
mês mais frio do ano. A precipitação é maior entre os meses de novembro a janeiro e o período mais seco estende-se de junho a agosto (Maia \& Baptista 2008).

\section{Preparo do material vegetal para análise qualitativa}

As porções medianas foliares de cinco indivíduos por espécie por ambiente foram fixadas em Formaldeído 37\%-Ácido acético P.A-Álcool etílico 50\% (1:1:18 v/v) e posteriormente conservada em álcool etílico $50 \%$. Estas amostras foram submetidas aos processos para inclusão em parafina segundo Johansen (1940) e seccionadas transversalmente $(10$ a $12 \mu \mathrm{m})$ em micrótomo rotativo Leica modelo RM 2145. As lâminas obtidas foram então desparafinadas, coradas com safranina e fast green (Johansen 1940) e montadas em verniz vitral incolor $500^{\circledR}$ (Paiva et al. 2006). Amostras frescas de folhas foram seccionadas na porção mediana com auxílio de micrótomo de Ranvier e submetidas a diferentes testes histoquímicos: sulfato ferroso (10\%)/formalina (4\%), cloreto férrico $10 \%$ e dicromato de potássio $10 \%$ para evidenciar compostos fenólicos; sudan III, sudan IV e sudan black para deposições lipídicas e floroglucinol acidificado para lignina. As preparações dos corantes e a indicação de teste controle ou branco seguiram as instruções de Kraus \& Arduin (1997). Os cortes corados foram montados em glicerina aquosa $50 \%$ (Kraus e Arduin 1997) ou verniz vitral incolor 500® (Paiva et al. 2006). Para a análise das faces da epiderme (vista frontal) foi empregada a técnica de maceração com solução de peróxido de hidrogênio e ácido acético glacial $(1: 1 \mathrm{v} / \mathrm{v})$ seguindo os procedimentos de Franklin (1945) modificados por Kraus e Arduin (1997). As lâminas permanentes e temporárias obtidas destas preparações foram analisadas através do microscópio ótico Olympus CX31 e fotografadas com câmera digital Olympus C-7070 wide zoom acoplada.

Para descrever a micromorfologia foliar sob microscopia eletrônica de varredura, as folhas foram fixadas em solução aquosa de glutaraldeído 2,5\% com tampão fosfato $0,1 \mathrm{M}(\mathrm{pH}$ 7,2-7,4), pós-fixadas em tetróxido de ósmio, desidratadas em série acetônica crescente, secadas ao ponto crítico, coladas com fita dupla face aos suportes e metalizadas com ouro (Souza 1998). As amostras foram analisadas e fotografadas em microscópio eletrônico de varredura modelo JEOL JSM $7001 \mathrm{~F}$ a $15 \mathrm{KV}$.

As descrições referentes à morfologia externa das folhas foram baseadas em Hickey \& Wolfe (1975), Leaf Architecture Working Group (1999) e Hickey \& King (2000).

\section{Preparo do material vegetal para análise quantitativa}

Foram coletadas 10 folhas completamente expandidas (uma folha por indivíduo) na zona de fundo da vereda e outras 10 folhas no cerrado sensu stricto de $M$. radula e de $T$. parviflora para a mensuração dos parâmetros quantitativos foliares. As folhas foram acondicionadas em sacos de papel pardo, colocadas dentro de isopor com gelo, levadas ime- diatamente ao laboratório, e escaneadas para mensuração da área foliar $\left(\mathrm{cm}^{2}\right)$ através do software livre ImageJ versão 1.43. Na sequência, as mesmas foram secas em estufa a $70^{\circ} \mathrm{C}$ por $48-72$ horas e pesadas unitariamente em balança de precisão para obtenção do valor da massa seca foliar (g). Para cada folha foi determinada a área foliar específica (AFE: $\mathrm{cm}^{2} / \mathrm{g}$ ), dividindo-se a área foliar pela massa seca foliar, e a massa foliar específica (MFE: $\mathrm{g} / \mathrm{cm}^{2}$ ), dividindo-se a massa seca foliar pela área foliar (Sobrado \& Medina 1980, Groom \& Lamont 1997).

O mesmo número de folhas $(\mathrm{n}=10$ por espécie por ambiente) foi utilizado para a mensuração do mesofilo. Os procedimentos para inclusão em parafina, seccionamento, montagem e registro fotográfico foram idênticos aos citados anteriormente. As medidas de espessura do mesofilo e dos parênquimas clorofilianos foram obtidas através do programa de análise de imagens Image-Pro Plus versão 4.5 (Media Cybernetics - Silver Spring, EUA), totalizando 50 medidas para cada espécie por ambiente.

Para a análise estatística utilizou-se ANOVA de um fator (local: vereda e cerrado sensu stricto), seguida de teste de Tukey $(\mathrm{P}<0,05)$ para diferenças entre as médias (Zar 2009). Todas as análises estatísticas foram realizadas através do software Statistica 7.

\section{Resultados}

\section{Descrição morfológica da lâmina foliar}

Lavoisiera bergii Cogn.

Folhas simples, sésseis, coriáceas e de superfície glabra. Não apresentam pecíolo e inserem-se no caule em ângulo de $20^{\circ}$ a $50^{\circ}$, imbricadas com filotaxia oposta cruzada. A lâmina foliar é nanófila e o formato é ovado de base truncada, ápice agudo e bordo serreado (Fig. 1A). A nervação é acródroma basal imersa, de difícil visualização.

Macairea radula (Bonpl.) DC.

Folhas simples, pecioladas, crassas e de superfície hirsuta. A disposição é oposta cruzada. A lâmina foliar é micrófila e o formato é elíptico-oblongo de base obtusa, ápice agudo e bordo inteiro e revoluto (Fig. 1B). A nervação acródroma suprabasal é impressa na face adaxial e muito saliente na face abaxial. As folhas dos indivíduos nos dois ambientes apresentam predação. Galhas entomógenas estão presentes nas axilas de folhas jovens.

\section{Trembleya parviflora (D. Don) Cogn.}

Folhas simples, pecioladas, coriáceas a cartáceas e sedosas. Apresenta filotaxia oposta cruzada. A lâmina foliar é micrófila e o formato é elíptico, com base levemente atenuada, ápice agudo, bordo inteiro e levemente revoluto (Fig. 1C). A nervação acródroma basal é impressa na face adaxial e pouco saliente na face abaxial. As folhas dos indivíduos nos dois ambientes apresentam predação. 

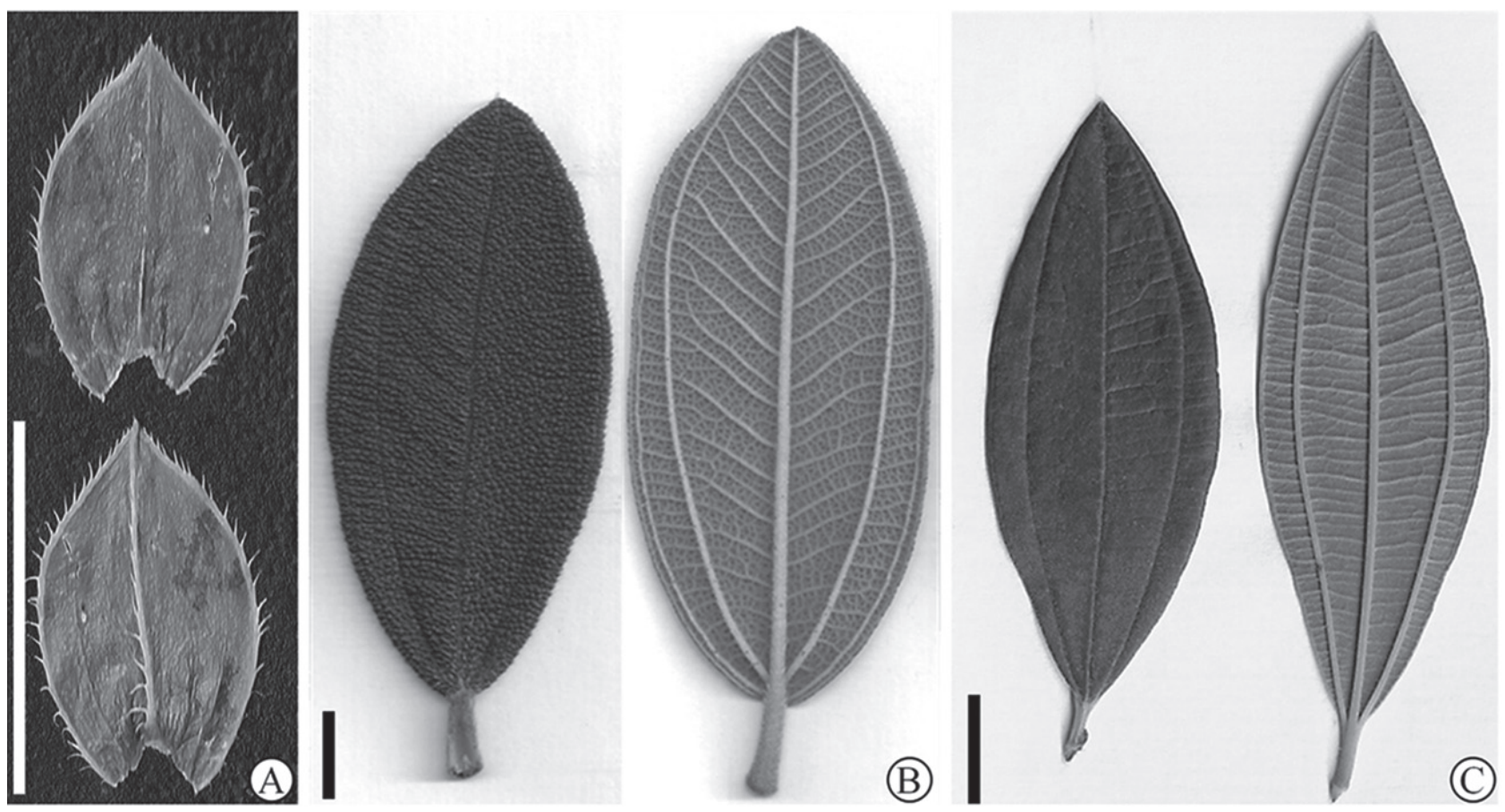

Figura 1. Vista adaxial (acima em A e à esquerda em B e C) e abaxial das folhas. A. Lavoisiera bergii Cogn. B. Macairea radula (Bonpl.) DC. C. Trembleya parviflora (D. Don) Cogn. Escalas: $1 \mathrm{~cm}$.

\section{Descrição anatômica da lâmina foliar}

Em secção transversal, L. bergii mostra as alas arqueadas em relação à nervura principal, dando formato "v" à lâmina foliar, chamado de carinato (Fig. 2A). M. radula apresenta a lâmina foliar com formato em zigue-zague ou plicado (Fig. 2B) e em T. parviflora a lâmina foliar é plana, com leve arqueamento próximo à nervura principal (Fig. 2C).

\section{Epiderme}

É uniestratificada nas três espécies. Algumas células de L. bergii apresentam projeções do protoplasto voltadas para a superfície da lâmina foliar (Fig. 3A), em ambas as faces. Nesses locais, a parede periclinal externa é menos espessa do que no restante da célula (Fig. 3B). A cutícula é delgada quando comparada com a parede celular em ambas as faces de L. bergii (Fig. 3A, 3H) e na face adaxial de M. radula (Fig. 3C) e de T. parviflora (Fig. 3D).

No plano paradérmico, as células epidérmicas comuns da face adaxial de L. bergii apresentam padrão diferenciado, com paredes anticlinais retas a levemente onduladas na região central e sinuosas na periferia da lâmina (Fig. 3E). $\mathrm{Na}$ face abaxial dessa espécie todas as células têm contorno sinuoso (Fig. 3F). Nas outras duas espécies as paredes anticlinais são retas na face adaxial e sinuosas na face abaxial.

M. radula e T. parviflora são hipoestomáticas com os estômatos no mesmo nível, ou levemente acima, das células epidérmicas comuns. Localizam-se exclusivamente nos sulcos entre as nervuras em M. radula (Fig. 2B) e principalmente nas evaginações da epiderme em T. parviflora (Fig. $3 \mathrm{G})$, as quais delimitam grandes câmaras subestomáticas
(Fig. 2C). A folha de L. bergii é anfiestomática e os estômatos estão no mesmo nível das demais células epidérmicas (Fig. $3 \mathrm{H})$. Na face adaxial, eles se concentram mais na periferia da lâmina, sendo escassos na região central. Cristas estomáticas cobertas pela cutícula (Fig. $3 \mathrm{H}-\mathrm{J}$ ) estão presentes nas três espécies. Os estômatos são diacíticos ou anisocíticos em todas as espécies analisadas.

Tricomas estão presentes nas três espécies, mas com localização, densidade e formatos diferenciados. L. bergii apresenta somente um tipo de tricoma glandular na axila das emergências situadas no bordo (Fig. 4A-B) e face abaxial da nervura principal, sendo as folhas consideradas glabras. $T$. parviflora tem, em ambas as faces, um único tipo de tricoma glandular (Fig. 4C), com pedúnculo unisseriado e cabeça glandular multicelular. M. radula possui tricomas somente na face abaxial identificados como tector unisseriado (Fig. 4D), glandular unisseriado, geminado ou não, de cabeça secretora unicelular (Fig. 4E-F), glandular bisseriado longo de cabeça secretora unicelular ou multicelular (Fig. 4G) e glandular bisseriado claviforme (Fig. 4H).

\section{Mesofilo}

L. bergii (Fig. 5A) e T. parviflora (Fig. 5B) têm mesofilo isobilateral, com parênquima paliçádico em camada única nas duas faces. O parênquima lacunoso apresenta 2 a 3 camadas de células. Na face abaxial de T. parviflora as células do parênquima paliçádico são menores do que na face adaxial e não apresentam deposição de compostos fenólicos (Fig. 5B). Em M. radula o mesofilo é dorsiventral (Fig. 5C), com parênquima paliçádico em camada única e 


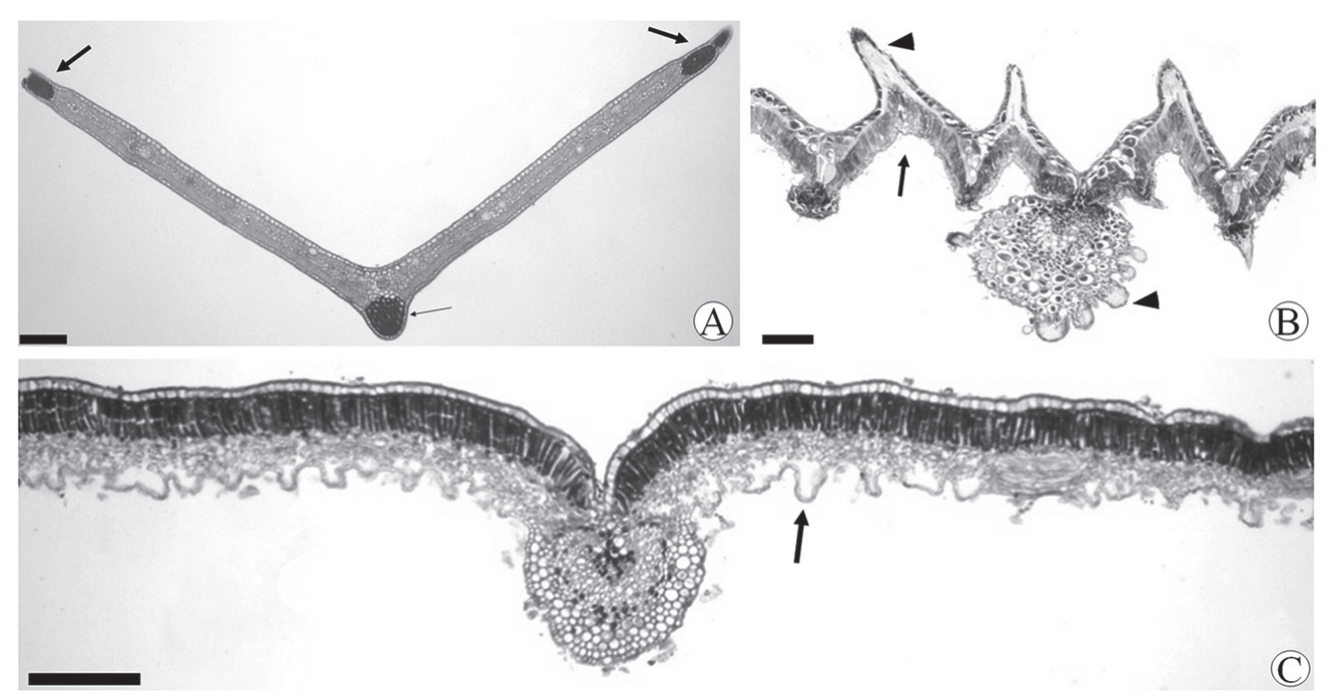

Figura 2. Secção transversal da lâmina foliar. A. Formato carinato de Lavoisiera bergii Cogn. com feixes esclerenquimáticos nos bordos e nervura principal (setas). B. Formato plicado de Macairea radula (Bonpl.) DC. com sulcos na face abaxial (seta) onde localizam-se os estômatos e emergências nas faces adaxial e abaxial (ponta de seta). C. Formato plano de Trembleya parviflora (D. Don) Cogn. com destaque para as evaginações da epiderme na face abaxial (seta). Escalas: $200 \mu \mathrm{m}$.

o lacunoso variando entre 3 a 5 camadas de células. Na face adaxial de $M$. radula está presente uma hipoderme, formada por uma a cinco camadas de células que se conectam com a extensão da endoderme nos feixes vasculares (Fig. 5C-D).

\section{Emergências}

Em L. bergii e $M$. radula ocorrem emergências formadas por esclerênquima, no entanto, a localização e algumas características celulares são diferentes. Nas folhas de $L$. bergii, fibras esclerenquimáticas formam feixes ao longo de todo o bordo, ápice e face abaxial da nervura principal (Fig. 2A) que, de espaço em espaço, se projetam originando as emergências tectoras revestidas pela epiderme (Fig. 4A).

Em M. radula, emergências tectoras são encontradas na face adaxial e emergências tectoras e glandulares na face abaxial (Fig. 5D). As emergências da face adaxial são formadas por esclereídes filiformes dispostos entre a hipoderme e o parênquima paliçádico. Essas esclereídes se conectam com as células da extensão da endoderme (Fig. 5C, 6A). A epiderme e a hipoderme revestem as emergências que se distribuem por toda a face adaxial (Fig. 5C-D). Na face abaxial, emergências glandulares (Fig. 5D, 6B) e tectoras são encontradas nas nervuras, com as emergências tectoras restritas à nervura principal e secundárias, não sendo encontradas nas nervuras de menor calibre. Ambas as emergências são formadas por esclereídes (Fig. 6B) de base ramificada que permeiam as células corticais e são revestidas pela epiderme. Tricomas glandulares e tectores podem ocorrer na base e na lateral destas emergências (Fig. 6B).

\section{Nervura principal}

As três espécies estudadas apresentam nervura principal do tipo côncavo-convexo (Fig. 7A-C). Em M. radula e T. parviflora a epiderme é seguida de colênquima em ambas as faces, o parênquima cortical ocorre principalmente na face abaxial e o feixe vascular principal é bicolateral, preenchido pela medula parenquimática. M. radula (Fig. 7A) e T. parviflora podem apresentar feixes vasculares anficrivais na região medular.

O parênquima paliçádico é geralmente contínuo na face adaxial de L. bergii (Fig. 7C). Porém, nas folhas que apresentam ângulo de inserção mais fechado, as células da região central, logo abaixo da epiderme na face adaxial, apresentam-se aclorofiladas e com a parede celular levemente mais espessa quando comparadas às da face abaxial ou à mesma região em folhas com ângulo de inserção mais aberto. (Fig. 7D). Os tecidos vasculares estão dispostos num feixe colateral, circundado pela endoderme, inseridos no parênquima clorofiliano. $\mathrm{Na}$ face abaxial a epiderme é seguida de feixe de fibras esclerenquimáticas (Fig. 7C), que se projetam em emergências tectoras semelhantes às do bordo (Fig. 4A).

\section{Inclusões celulares}

Idioblastos com drusas estão presentes no parênquima lacunoso das 3 espécies, sendo maiores em L. bergii (Fig. 5A). A deposição de compostos fenólicos é bem marcante nos parênquimas paliçádico, cortical, medular e parênquima do floema e endoderme de $M$. radula e T. parviflora, na hipoderme de $M$. radula e somente no parênquima do floema em L. bergii. Gotículas de óleo foram evidenciadas no mesofilo de $M$. radula e T. parviflora.

Os indivíduos de $M$. radula e $T$. parviflora não apresentaram diferenças qualitativas quanto à composição e organização estrutural das lâminas foliares em relação ao ambiente de ocorrência, seja na zona de fundo da vereda ou no cerrado sensu stricto. 

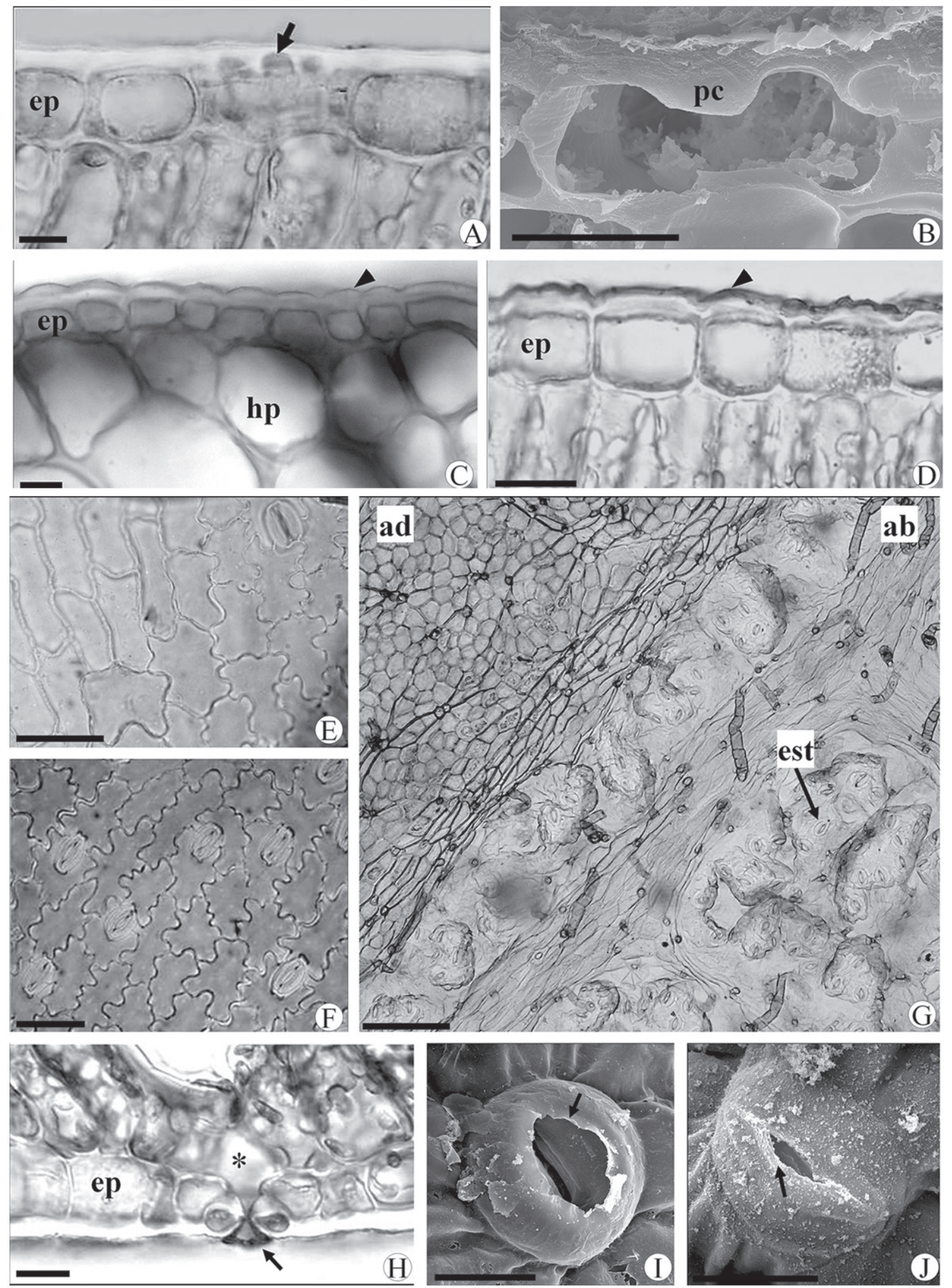

Figura 3. Epiderme. A-B. Lavoisiera bergii Cogn. A. Projeções do protoplasto (seta) na célula epidérmica da face adaxial. B. Microscopia eletrônica de varredura (MEV) com detalhe do espessamento diferencial da parede celular (pc). C-D. Face adaxial. C. Macairea radula (Bonpl.) DC. e de Trembleya parviflora (D. Don) Cogn. (D) mostrando o espessamento da parede periclinal externa e a cutícula (ponta de seta). E-F. Vista paradérmica de L. bergii. E. Face adaxial. F. Face abaxial. G. Vista paradérmica das faces adaxial (ad) e abaxial (ab) de T. parviflora. H. Face abaxial de L. bergii com destaque para as cristas estomatíferas (seta) e a câmara subestomática (asterisco). I-J. MEV dos estômatos de M. radula (I) e T. parviflora (J) com destaque para as cristas estomatíferas. ep: epiderme; est: estômato; hp: hipoderme. Escalas: A-C, H-J (10 $\mu \mathrm{m}), \mathrm{D}-\mathrm{F}(50 \mu \mathrm{m}), \mathrm{G}(200 \mu \mathrm{m})$. 

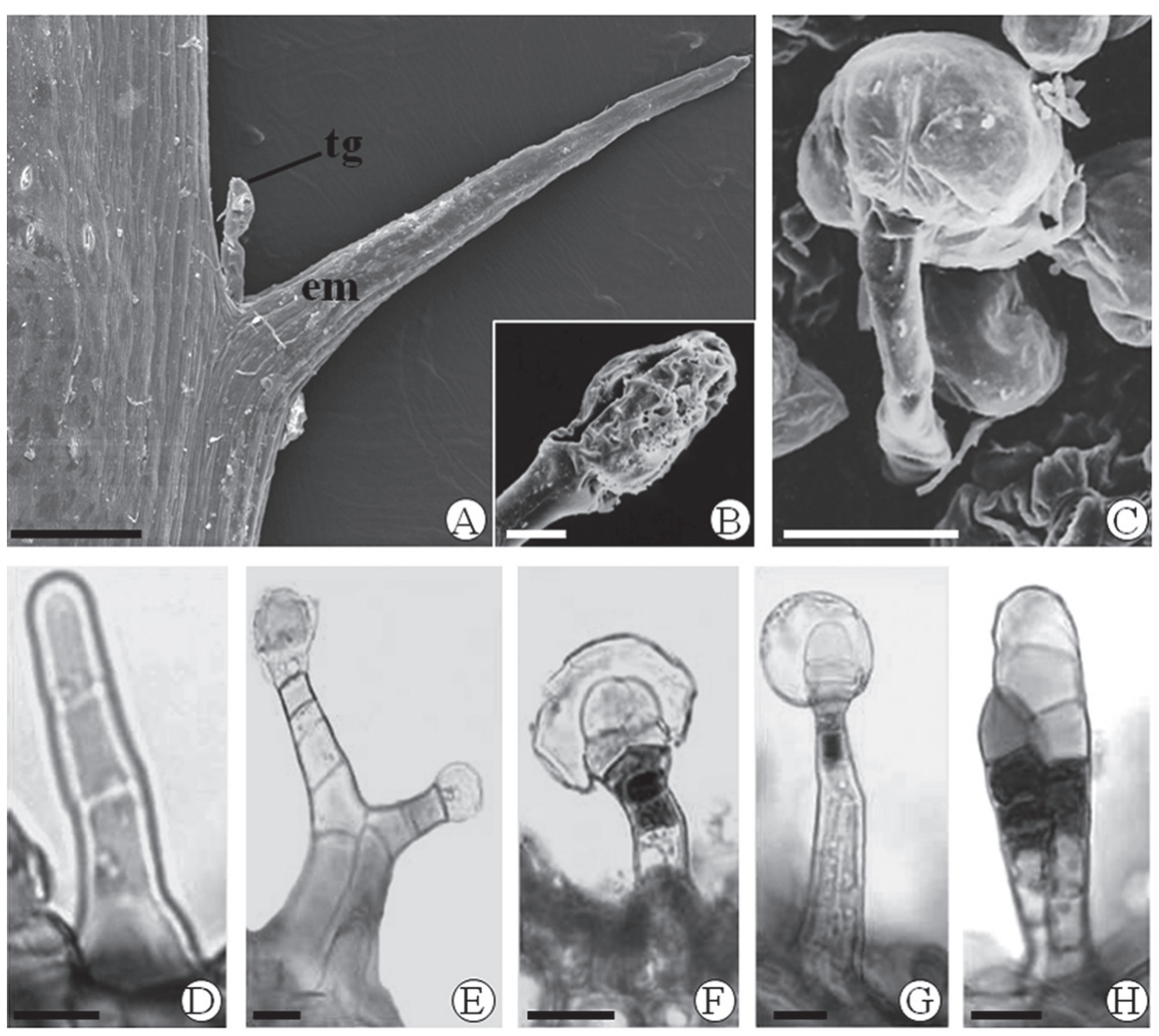

Figura 4. Tricomas. Microscopia eletrônica de varredura (A-C) e microscopia óptica (D-H). A-B. Lavoisiera bergii Cogn. A. Bordo foliar com tricoma glandular (tg) na axila da emergência (em). B. Detalhe da extremidade distal do tricoma glandular. C. Tricoma glandular de Trembleya parviflora (D. Don) Cogn. D-H. Tricomas em Macairea radula (Bonpl.) DC. D. Tector unisseriado. E-F. Glandular unisseriado. E. Geminado. F. Não geminado. G. Glandular bisseriado. H. Glandular bisseriado claviforme. Escalas: A (100 $\mu \mathrm{m})$; B, E $(20 \mu \mathrm{m})$; C;H $(10 \mu \mathrm{m})$, D $(5 \mu \mathrm{m})$.

\section{Dados quantitativos}

Embora não tenham sido observadas diferenças qualitativas, as lâminas foliares de M. radula e T. parviflora mostraram diferenças quantitativas significativas em alguns parâmetros em relação ao ambiente de coleta. A espessura do mesofilo e dos parênquimas clorofilianos, a massa foliar, a área foliar específica (AFE) e a massa foliar específica (MFE) apresentaram diferença estatística significativa $(\mathrm{P}<0,05, \mathrm{Ta}-$ bela 1), indicando que as folhas da vereda são mais espessas que as folhas do cerrado sensu stricto.

\section{Discussão}

A epiderme com paredes periclinais externas espessadas, os estômatos com cristas estomáticas, a pilosidade, o mesofilo denso e a esclerificação, apresentadas pelas espécies de Melastomataceae desse estudo, são características comuns em folhas de espécies do cerrado (Bieras 2006), e indicam uma condição de escleromorfismo foliar (Esau 1976; Turner 1994). De forma geral, estes caracteres foliares estão relacionados com a redução na perda de água para a atmosfera em ambientes com deficiência de água (Johnson 1980; Zaman \& Padmesh 2009) ou quantidades insuficientes de nutrientes (Medina et al. 1990; Feller 1996; GonçalvesAlvim et al. 2004) no solo.

Embora as espécies analisadas ocorram em ambiente com disponibilidade de água, a radiação solar direta e incidência de ventos, muito comuns em ambientes abertos como a vereda, aumentam a possibilidade de perda de água por evapotranspiração (Larcher 2000). Além disso, o sistema radicular e a parte basal do caule destas espécies permanecem alagados durante a maior parte do ano. De acordo com Kozlowski \& Pallardy (1984), esta condição de hipoxia junto ao sistema radicular altera a absorção de nutrientes como nitrogênio, fósforo e potássio. Tais nutrientes, segundo Furlani (2004) são essenciais para o estabelecimento e desenvolvimento de plantas e podem influenciar a estruturação dos tecidos nas lâminas foliares.

Projeções protoplasmáticas semelhantes às encontradas nas células epidérmicas de $L$. bergii ocorreram em outras espécies de Lavoisiera de campos rupestres (Sousa 1997), sendo essa uma característica comum no gênero. Esse mesmo tipo de projeção também foi encontrado em espécies de Myrtaceae (Fontenelle et al. 1993; Fontenelle et al. 1994; Callado 1997). Gomes et al. (2009), discutindo a importância evolutiva desta característica nas Myrtaceae, propõem esse estado de caráter como apomórfico, tendo 


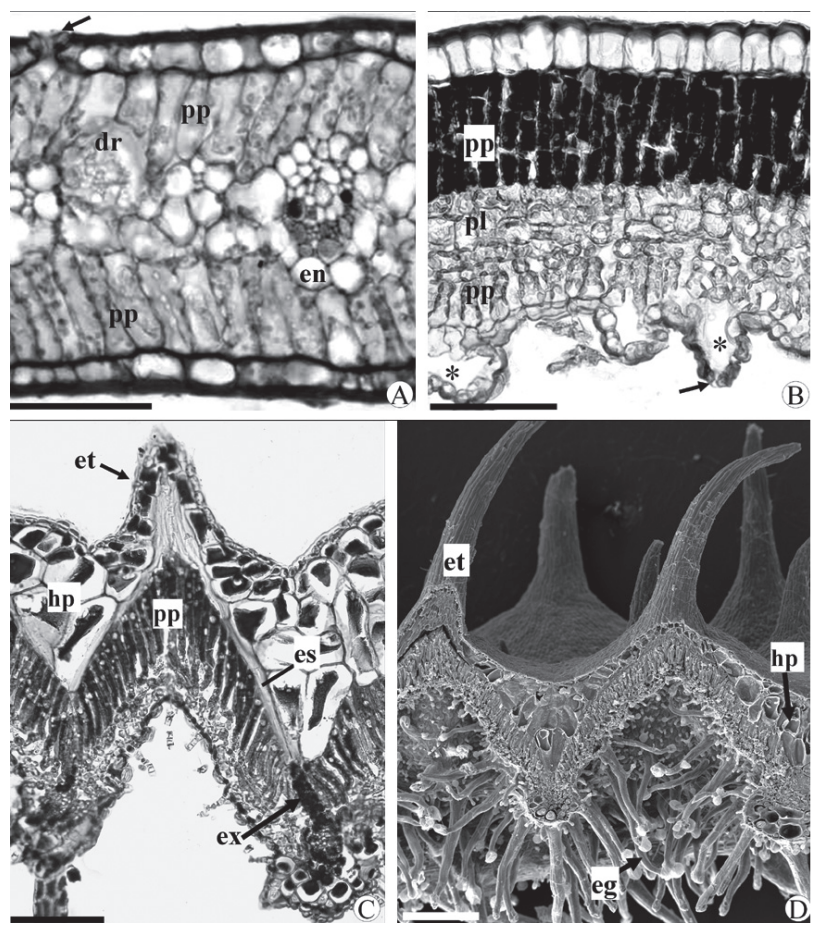

Figura 5. Corte transversal da lâmina foliar. A. Mesofilo isobilateral em Lavoisiera bergii Cogn. e estômato na face adaxial. B. Mesofilo isobilateral em Trembleya parviflora (D. Don) Cogn. com estômatos e câmaras subestomáticas na face abaxial. C. Mesofilo dorsiventral em Macairea radula (Bonpl.) DC. com destaque para os esclereídes (es) entre a hipoderme (hp) e o parênquima paliçádico (pp) D. Microscopia eletrônica de varredura com destaque para as emergências tectoras (et) e glandulares (eg) e a hipoderme (hp). Asterisco: câmaras subestomáticas; dr: drusa; en: endoderme; pl: parênquima lacunoso; seta: estômatos. Escalas: $100 \mu \mathrm{m}$.

surgido em momentos diferentes e de modo independente ao longo de sua evolução, podendo ou não ter relação com o ambiente. Gomes et al. (2009) relacionam essas projeções com as encontradas em células de transferência, que promovem aumento da superfície de contato e trocas entre as células. Como as projeções encontradas em L. bergii ocorrem somente nas paredes periclinais externas das células epidérmicas, é mais provável que elas estejam relacionadas à absorção/exsudação ou percepção de estímulos com o meio externo, conforme proposto por Fontenelle et al. (1993).

$\mathrm{Na}$ tribo Tibouchiniae, à qual pertence $M$. radula, o mesofilo dorsiventral parece ser o mais comum, sendo encontrado em Acisanthera alsinaefolia (Reis et al. 2005), Chaetolepis lindeniana (Ely \& Torres 2003), diferentes espécies de Tibouchina (Reis et al. 2005; Bieras 2006), em Microlepis oleaefolia (Reis et al. 2005; Milanez \& Machado 2007) e em Marcetia taxifolia (Gardoni et al. 2007). Metcalfe e Chalk (1979) o consideram como representativo da família Melastomataceae, sendo encontrado na maioria dos gêneros já estudados (Mentink \& Baas 1992; Souza \& Marquete 2000; Reis et al. 2005; Bieras 2006; Oliveira 2007; Reginato et al. 2009).

O mesofilo isobilateral, no entanto, apresenta distribuição mais restrita entre os grupos vegetais e, apesar de não ser citado para Melastomataceae por Metcalfe \& Chalk (1979), parece ser bem característico da tribo Microliceae, pois além de ocorrer em L. bergii e T. parviflora neste estudo, também foi citado para outras espécies de Lavoisiera (Sousa 1997) e em Microlicia polystemma (Reis et al. 2005). Emergências foliares como as encontradas em $L$. bergii e $M$. radula foram consideradas tricomas por Wurdack (1986) e Mentink \& Baas (1992), porém os estudos ontogênicos realizados nessas espécies (observações pessoais) e em Microlepis oleaefolia (Milanez \& Machado 2007) indicam que essas estruturas são formadas por células que se originam da protoderme e do meristema fundamental. Tais emergências são comuns em Melastomataceae e podem desempenhar diferentes funções na planta como ressaltado por Barroso (1991).

O contato entre as esclereídes filiformes das emergências e as células da extensão da endoderme, mostrados em $M$. radula, pode representar uma conexão com os tecidos vasculares das nervuras. Milanez \& Machado (2007) também destacam esta possível conexão das emergências com os tecidos vasculares em Microlepis oleaefolia. Além disso, análises ultraestruturais e histoquímicas das paredes celulares das esclereídes demonstraram microcanais permeáveis à água e nutrientes, indicando que estas estruturas estariam relacionadas ao transporte de substâncias, podendo absorver ou exsudar soluções (Milanez \& Machado 2007).

$\mathrm{Em} L$. bergii não foi identificada qualquer conexão entre as esclereídes e o tecido vascular. No entanto, a presença de traqueídes na base e ao longo das emergências foi ressaltada por Sousa (1997) para algumas espécies de Lavoisiera de campo rupestre, inclusive em representantes da secção Cataphractae, à qual pertence $L$. bergii. Nesta espécie, a função das emergências parece estar mais relacionada à proteção contra a herbivoria do que com as trocas com o meio externo, como discutido no parágrafo seguinte.

A ausência de predação nas folhas de L. bergii pode estar associada com a esclerificação ao longo do bordo e na face abaxial da nervura principal. A esclerificação do bordo também foi a principal característica anatômica apontada por Ribeiro et al. (2010) para explicar a menor taxa de predação em Lavoisiera imbricata e Baccharis imbricta (Asteraceae) quando comparadas com outras espécies de Melastomataceae e Lythraceae. Outros fatores que conferem proteção contra a herbivoria, como compostos fenólicos e tricomas (Esau 1976; Fahn 1982; Turner 1994), são menos expressivos nessa espécie. No entanto, nas outras duas espécies analisadas, a pilosidade mais intensa e a maior quantidade de compostos fenólicos nos tecidos não evitaram que suas folhas fossem predadas. Embora a esclerificação nas emergências de M. radula possa contribuir para esse tipo de defesa, a quantidade e a disposição destas estruturas podem ter minimizado a sua influência na proteção.

Compostos fenólicos são considerados como protetores contra a incidência de raios UV-B, agindo como filtros ou antioxidantes (Landry et al. 1995; Booij-James 


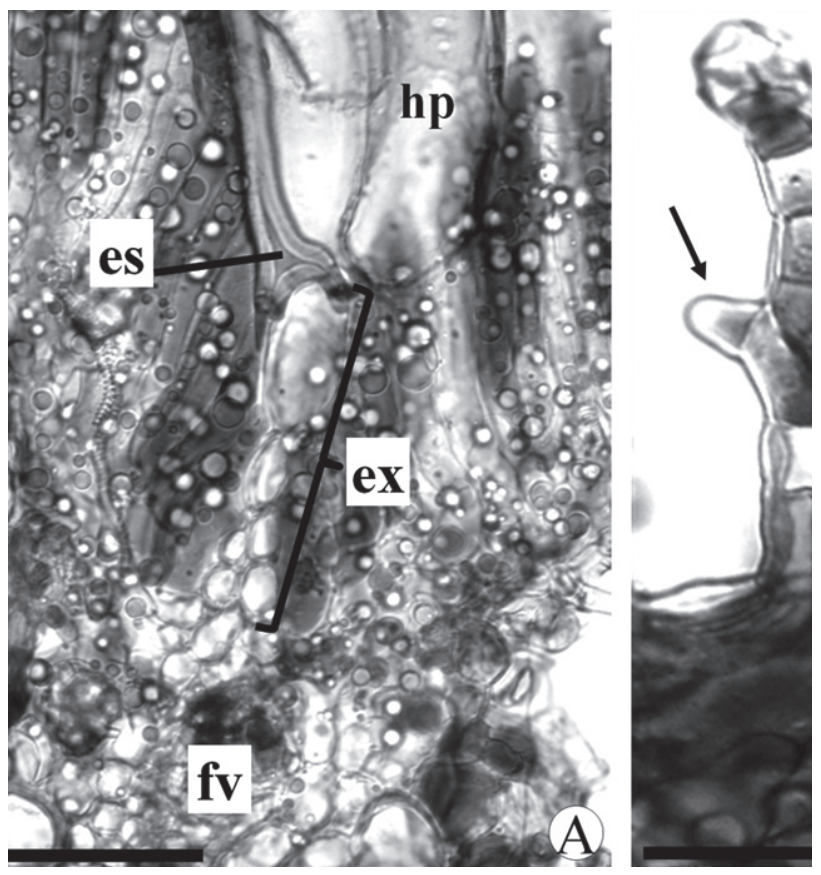

Figura 6. Emergências em Macairea radula (Bonpl.) DC. A. Detalhe mostrando a base da esclereíde (es) em contato com a extensão da endoderme (ex). B. Emergência glandular com esclereídes (es) na base e com tricoma tector (seta) na lateral. fv: feixe vascular. Escalas: $50 \mu \mathrm{m}$.

et al. 2000; Bieza \& Lois 2001; Figueroa et al. 2009) e sua presença nas folhas de M. radula e T. parviflora pode contribuir para diminuir os efeitos nocivos da alta intensidade luminosa na zona de fundo e meio da vereda. A quantidade expressivamente maior destes compostos nestas duas espécies, em comparação com L. bergii, pode ser uma resposta fisiológica à predação, pois tanto a radiação UV-B quanto a herbivoria são considerados estimuladores na biossíntese destes metabólitos secundários (Izaguirre et al. 2007).

Feixe vascular colateral ou bicolateral na nervura principal e idioblastos com drusas no mesofilo são comuns à família Melastomataceae (Baas 1981; Keating 1984), mas não específicos, embora os tipos de cristais, conjugados a tipos estomatais, tenham sido usados para delimitar alguns gêneros e subfamílias (Baas 1981).
As lâminas foliares dos indivíduos de M. radula e $T$. parviflora que se desenvolvem na vereda e no cerrado sensu stricto não apresentaram diferenças qualitativas, mas demonstram plasticidade quantitativa. Os dados de massa foliar específica (MFE) e área foliar específica (AFE) demonstram que as folhas no ambiente de vereda apresentam maior massa por unidade de área do que as folhas dos indivíduos localizados no cerrado sensu stricto. Esses dados corroboram com os encontrados por Baruch et al. (2000) para quatro espécies de Melastomataceae invasoras, submetidas a diferentes níveis de luminosidade e estresse hídrico. Os resultados revelaram valores menores de MFE (e maiores para AFE) com a redução da luminosidade, independente da condição hídrica do solo (Baruch et al. 2000).

No entanto, Herrera et al. (2009) verificaram diminuição dos valores na AFE em espécies arbóreas amazônicas submetidas a alagamento sazonal, condição a que estão expostos os indivíduos na zona de fundo da vereda, mostrando que este fator também pode influenciar quantitativamente a anatomia foliar.

Os indivíduos da vereda têm parênquimas clorofilianos e mesofilo mais espessos do que os indivíduos sujeitos ao sombreamento no cerrado sensu stricto. Esta relação entre espessura dos parênquimas clorofilianos, mesofilo e a intensidade luminosa também foi destacado por Rôças et al. (1997) em Alchornea triplinervia, por Marques et al. (1999) para Sebastiania myrtilloides, por Marques et al. (2000) em duas espécies de Miconia e por Rossato \& Kolb (2010) em Gochnatia polymorpha, onde os indivíduos de ambientes que receberam maior luminosidade mostraram maior espessamento no mesofilo e parênquima clorofiliano.

Conclui-se, portanto, que as análises anatômicas qualitativas e quantitativas das lâminas foliares das espécies de Melastomataceae estudadas mostram que Lavoisiera bergii, Macairea radula e Trembleya parviflora possuem características estruturais escleromórficas que podem ter contribuído para o estabelecimento nas zonas abertas de fundo da vereda. Além disso, as diferenças quantitativas apresentadas pelas lâminas foliares de M. radula e T. parviflora demons-
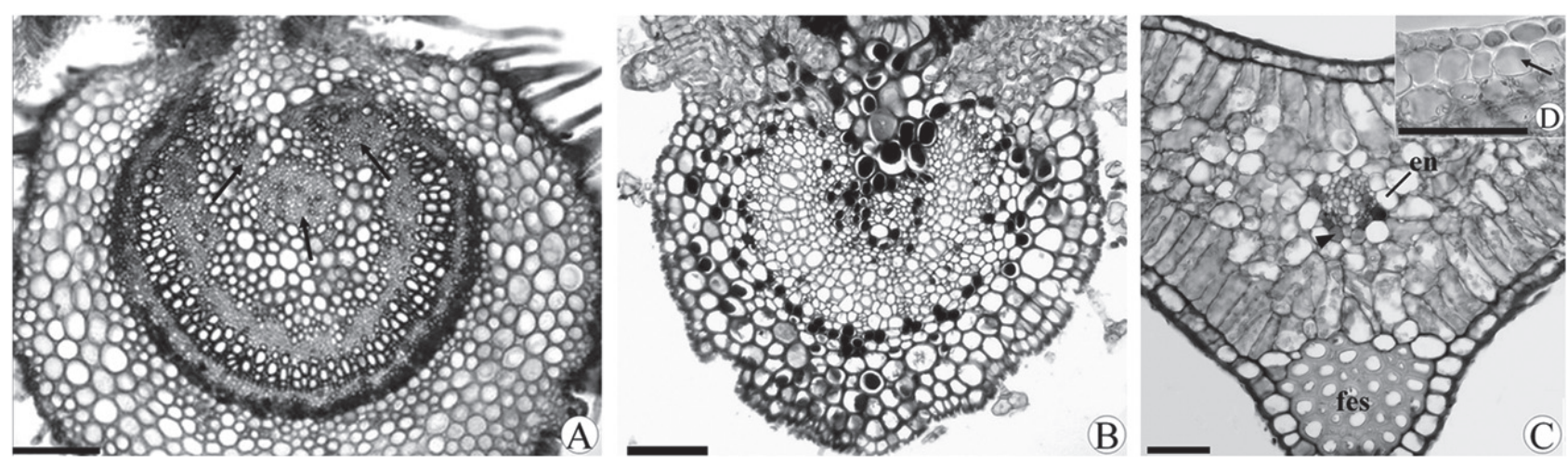

Figura 7. Nervura principal. A. Feixe bicolateral e feixes anficrivais na medula (setas) em Macairea radula (Bonpl.) DC. B. Feixe bicolateral em Trembleya parviflora (D. Don) Cogn. C-D Lavoisiera bergii Cogn. C. Feixe colateral com endoderme (en) bem definida e feixes de fibras esclerenquimáticas (fes) na face abaxial. D. Detalhe do parênquima na região central adaxial, com células aclorofiladas e paredes mais espessas (seta). Escalas: $100 \mu \mathrm{m}$. 
Tabela 1. Parâmetros anatômicos e morfológicos (média \pm erro padrão, $\mathrm{n}=10$ ) das espécies de Melastomataceae encontradas nos dois ambientes.

\begin{tabular}{lcccc}
\hline & \multicolumn{2}{c}{ Macairea radula (Bonpl.) DC. } & \multicolumn{2}{c}{ Trembleya parviflora (D. Don) Cogn. } \\
\cline { 2 - 5 } & Vereda & $\begin{array}{c}\text { Cerrado } \\
\text { sensu strito }\end{array}$ & Vereda & $\begin{array}{c}\text { Cerrado } \\
\text { sensu strito }\end{array}$ \\
\hline Espessura & & & & \\
$\quad$ Mesofilo $(\mu \mathrm{m})$ & $105,81 \pm 4,69$ & $87,93 \pm 2,77^{*}$ & $181,32 \pm 4,06$ & $140,83 \pm 4,26^{*}$ \\
Parênquima paliçádico $(\mu \mathrm{m})$ & $69,40 \pm 3,53$ & $59,05 \pm 2,18^{*}$ & $135,18 \pm 3,4$ & $104,96 \pm 3,49^{*}$ \\
Parênquima lacunoso $(\mu \mathrm{m})$ & $36,41 \pm 1,66$ & $28,88 \pm 1,39^{*}$ & $51,81 \pm 3,57$ & $37,85 \pm 1,21^{*}$ \\
Massa seca foliar $(\mathrm{g})$ & $0,35 \pm 0,06$ & $0,27 \pm 0,02^{*}$ & $0,085 \pm 0,007$ & $0,056 \pm 0,004^{*}$ \\
Área foliar $\left(\mathrm{cm}^{2}\right)$ & $11,71 \pm 0,74$ & $13,44 \pm 1,01^{\text {ns }}$ & $6,49 \pm 0,49$ & $5,48 \pm 0,36^{\mathrm{ns}}$ \\
AFE $\left(\mathrm{cm}^{2} \mathrm{~g}^{-1}\right)$ & $42,98 \pm 1,28$ & $50,03 \pm 1,70^{*}$ & $74,47 \pm 2,38$ & $97,92 \pm 2,32^{*}$ \\
MFE $\left(\mathrm{g} \mathrm{cm}^{-2}\right)$ & $0,0235 \pm 0,0007$ & $0,021 \pm 0,0007^{*}$ & $0,014 \pm 0,0004$ & $0,010 \pm 0,0002^{*}$ \\
\hline
\end{tabular}

Os valores identificados com $\left(^{*}\right)$ apresentaram diferença estatística significativa $(\mathrm{P}<0,05)$ e os valores indicados com $(\mathrm{ns})$ não apresentaram diferença estatística significativa entre os ambientes para cada uma das espécies analisadas. Legenda: AFE: área foliar específica; MFE: massa foliar específica.

tram plasticidade entre os indivíduos localizados na zona de fundo da vereda e no cerrado sensu stricto adjacente. Quanto ao aspecto taxonômico, algumas características encontradas nestas espécies reforçam a importância das mesmas para a descrição da família como a nervação acródroma, os feixes bicolaterais na medula e tricomas diversos e geralmente complexos (Judd et al. 2009). Outros caracteres como organização do mesofilo, tipos e estruturação das emergências podem apresentar relevância taxonômica dentro da família e deverão ser melhor analisados.

\section{Agradecimentos}

Agradecemos a Dra. Cássia Munhoz - UnB pelo auxílio na identificação botânica dos espécimes, ao Conselho Nacional de Pesquisa (CNPq) pela concessão da bolsa de doutorado da primeira autora e a Dra. Suzane Margareth Fank de Carvalho pela revisão do manuscrito.

\section{Referências bibliográficas}

Alves, M.V.; Estelita, M.E.M.; Wanderley, M.G.L. \& Thomas, W.W. 2002. Aplicações taxonômicas da anatomia foliar das espécies brasileiras de Hypolythrum Rich. (Cyperaceae). Revista Brasileira de Botânica 25(1): 1-9.

Amaral, A.F. 2002. Alterações decorrentes da queima e corte na vegetação natural de uma vereda em Uberlândia - MG. Dissertação de Mestrado, Universidade Federal de Uberlândia, Uberlândia.

Anderson, L.C. \& Creech, J.B. 1975. Comparative leaf anatomy of Solidago and related Asteraceae. American Journal of Botany 62(5): 486-493.

Araújo, G.M.; Barbosa, A.A.A.; Arantes, A.A. \& Amaral, A.F. 2002. Composição florística de veredas no município de Uberlândia, MG. Revista Brasileira de Botânica 25(4): 475-493.

Baas, P. 1981. A note on stomatal types and crystals in the leaves of Melastomataceae. Blumea 27: 475-479.

Barbosa-Silva, D. 2007. Distribuição de espécies de Melastomataceae Juss. ao longo de um gradiente em três fitofisionomias do bioma Cerrado na Estação Ecológica de Águas Emendadas, Planaltina-DF. Dissertação de Mestrado, Universidade de Brasília, Brasília.

Barroso, G. M. 1991. Sistemática de Angiospermas do Brasil. v. 2. Viçosa, Imprensa da Universidade de Viçosa.
Baruch, Z; Pattison, R.R. \& Goldstein, G. 2000. Responses to light and water availability of four invasive Melastomataceae in the Hawaiian Islands. International Journal of plant science 161(1): 107-118.

Bieras, A.C. \& Sajo, M.G. 2004. Anatomia foliar de Erythroxylum P. Browne (Erythroxylaceae) do Cerrado do Estado de São Paulo, Brasil. Acta Botanica Brasilica 18(3): 601-612.

Bieras, A. C. 2006. Morfologia e anatomia foliar de dicotiledôneas arbóreo-arbustivas do Cerrado de São Paulo, Brasil. Tese de Doutorado, Universidade Estadual Paulista, Rio Claro.

Bieras, A.C. \& Sajo, M.G. 2009. Leaf structure of the cerrado (Brazilian savanna) woody plants. Trees 23: 451-471.

Bieza, K \& Lois, R. 2001. An Arabidopsis mutant tolerant to lethal ultraviolet-B levels shows constitutively elevated accumulation of flavonoids and other phenolics. Plant Physiology 126: 1105-1115.

Boeger, M.R.T.; Gluzezak, R.M.; Pil, M.W.; Goldenberg, R. \& Medri, M. 2008. Variabilidade morfológica foliar de Miconia sellowiana (DC.) Naudin (Melastomataceae) em diferentes fitofisionomias no Estado do Paraná. Revista Brasileira de Botânica 31(3): 443-452.

Booij-James, I.S.; Dube, S.K.; Jansen, M.A.K.; Edelman, M. \& Mattoo, A.K. 2000. Ultraviolet-B radiation impacts light-mediated turnover of the photosystem II reaction center heterodimer in Arabidopsis mutants altered in phenolic metabolism. Plant Physiology 124: 1275-1284.

Brown, R.H. \& Hattersley, P.W. 1989. Leaf anatomy of C3-C4 species as related to evolution of C4 photosynthesis. Plant Physiology 91: 1543-1550.

Callado, C.H. 1997. Anatomia foliar de Eugenia cuprea (Berg.) Ndz. e Marlieria suaveolens Gard. (Myrtaceae). Rodriguésia 45/49: 25-37.

Eiten, G. 2001. Vegetação natural do Distrito Federal. Brasília, SEBRAE.

Ely, F. \& Torres, F. 2003. Adaptaciones anatómico-estructurales foliares de Chaetolepis lindeniana (Naud.) Triana a lo largo de um gradiente altitudinal em el Páramo Del Parque Nacional Sierra Nevada de Mérida (Venezuela). Plantula 3(2): 101-115.

Esau, K. 1976. Anatomia das plantas com sementes. São Paulo, EdgardBlücher.

Fahn, A. 1982. Plant anatomy. Oxford, Pergamon Press.

Feller, I.C. 1996. Effects of nutrient enrichment on leaf anatomy of dwarf Rhizophora mangle L. (red mangrove). Biotropica 28(1): 13-22.

Figueroa, F.L.; Korbee, N.; Carrillo, P.; Medina-Sánchez, J.M.; Mata, M.; Bonomi, J. \& Sánchez-Castillo, P.M. 2009. The effects of UV radiation on photosynthesis estimated as chlorophyll fluorescence in Zygnemopsis decussata (Chlorophyta) growing in a high mountain lake (Sierra Nevada, Southern Spain). Journal of Limnology 68(2): 206-216.

Fontenelle, G.B.; Gomes, D.M.S. \& Machado, R.D. 1993. Anatomia foliar de Gomidesia martiana Berg. e Gomidesia fenzliana Berg. (Myrtaceae). Revista Brasileira de Botânica 16: 17-30.

Fontenelle, G.B., Costa, C.G. \& Machado, R.D. 1994. Foliar anatomy and micromorphology of eleven species of Eugenia L. (Myrtaceae). Botanical Journal of the Linnean Society 115: 111-133. 
Franklin, G.L. 1945. Preparation of thin sections of synthetic resins and wood-resin composites, and a new macerating method for wood. Nature 155 (3924): 51

Furlani, A.M.C. 2004. Nutrição mineral. In: Kerbauy, G.B. (Org.). Fisiologia Vegetal. Rio de Janeiro, Guanabara Koogan.

Gardoni, L.C.; Isaias, R.M.S. \& Vale, F.H.A. 2007. Morfologia e anatomia foliar de três morfotipos de Marcetia taxifolia (A. St. Hil.) DC. (Melastomataceae) na Serra do Cipó, MG. Revista Brasileira de Botânica 30(3): 487-500.

Gomes, S.M.; Somavilla, N.S.D.; Gomes-Bezerra, K.M.; Miranda, S.C.; De-Carvalho, P.S. \& Graciano-Ribeiro, D. 2009. Anatomia foliar de espécies de Myrtaceae: contribuições à taxonomia e filogenia. Acta Botanica Brasilica 23(1): 223-238.

Gonçalves-Alvim, S.J.; Korndorf, G. \& Fernandes, G.W. 2004. Sclerophylly in Qualea parviflora (Vochysiaceae): influence of herbivory, mineral nutrients, and water status. Plant Ecology 187:153-162.

Groom, P.K. \& Lamont, B.B. 1997. Xerophytic implications of increased sclerophylly: interactions with water and light in Hakea psilorrhyncha seedlings. New Phytologyst 136: 231-237.

Guimarães, P.J.F. \& Martins, A.B. 1997. Tibouchina sect. Pleroma (D. Don) Cogn. (Melastomataceae) no estado de São Paulo. Revista Brasileira de Botânica 20(1): 11-33.

Guimarães, A.J.M.; Araújo, G.M. \& Corrêa, G.F. 2002. Estrutura fitosssociológica em área natural e antropizada de uma vereda em Uberlândia, MG. Acta Botanica Brasilica 16(3): 317-329.

Herrera, A.; Escala, M. \& Rengifo, E. 2009. Leaf anatomy changes related to physiological adaptations to flooding in Amazonian tree species. Brazilian Journal of Plant Physiology 21(4): 301-308.

Hickey, L.J. \& Wolfe, J.A. 1975. The bases of Angiosperm phylogeny: vegetative morphology. Annals of the Missouri Botanical Garden 62(3): 538-589.

Hickey, M. \& King, C. 2000. The Cambridge illustrated glossary of botanical terms. Cambridge, University Press.

Izaguirre, M.M.; Mazza, C.A.; Svatos, A.; Baldwin, I.T. \& Ballar, C.L. 2007. Solar ultraviolet-B radiation and insect herbivory trigger partially overlapping phenolic responses in Nicotiana attenuata and Nicotiana longiflora. Annals of Botany 99: 103-109.

Jaakola, L.; Määttä-Riihinen, K.; Kärenlampi, S. \& Hohtola, A. 2004. Activation of flavonoid biosynthesis by solar radiation in bilberry (Vaccinium myrtillus L.) leaves. Planta 218: 721-728.

Johansen, D.A. 1940. Plant Microtechnique. New York, Mc Graw Hill Book.

Johnson, C.T. 1980. The leaf anatomy of Leptospermum Forst. (Myrtaceae). Australian Journal of Botany 28: 77-104.

Judd, W.S.; Campbell, C.S.; Kellogg, E.A.; Stevens, P.F. \& Donoghue, M.J. 2009. Sistemática Vegetal: um enfoque filogenético. 3ed. Porto Alegre, Artmed.

Justo, C.F.; Soares, A.M.; Gavilanes, M.L. \& Castro, E.M. 2005. Plasticidade anatômica das folhas de Xylopia brasiliensis Sprengel (Annonaceae). Acta Botanica Brasilica 19(1): 111-123.

Karban, R.E. \& Baldwin, I.T. 1997. Induced responses to herbivory. Chicago, The University of Chicago Press.

Keating, R.C. 1984. Leaf histology and its contribution to relationships in the Myrtales. Annals of the Missouri Botanical Garden 71: 801-823.

Kocsis, M.; Darók, J. \& Borhidi, A. 2004. Comparative leaf anatomy and morphology of some neotropical Rondeletia (Rubiaceae) species. Plant Systematic and Evolution 248: 205-218.

Kozlowski, T.T. \& Pallardy, S.G. 1984. Effect of flooding on water, carbohydrate, and mineral relations. Pp.129-163. In: Kozlowski, T.T. (Org.). Flooding and plant growth. Califórnia, Academic Press.

Kraus, J.E. \& Arduin, M. 1997. Manual básico de métodos em morfologia vegetal. Rio de Janeiro, EDUR.

Landry, L.G.; Chapple, C.C.S. \& Last, R.L. 1995. Arabidopsis mutants lacking phenolic sunscreens exhibit enhanced Ultraviolet-B injury and oxidative damage. Plant Physiology 109: 1159-1166.

Larcher, W. 2000. Ecofisiologia Vegetal. São Paulo, RiMA.

Leaf Architecture Working Group. 1999. Manual of leaf architecture: morphological description and categorization of dicotyledonous and net-veined monocotyledonous angiosperms. Washington, Smithsonian Institution.
Lindorf, H. 1997. Wood and leaf anatomy in Sessea corymbiflora from an ecological perspective. IAWA Journal 18(2): 157-168.

Maia, J.M.F. \& Baptista, G.M.M. 2008. Clima. In: Fonseca, F.O (Org.) Águas Emendadas. Brasília, Seduma.

Marques, A.R.; Garcia, Q.S. \& Fernades, G.W. 1999. Effects of Sun and shade on leaf structure and sclerophylly of Sebastiania myrtilloides (Euphorbiaceae) from Serra do Cipó, Minas Gerais, Brazil. Boletim de Botânica da Universidade de São Paulo 18: 21-27.

Marques, A.R.; Garcia, Q.S.; Rezende, J.L.P. \& Fernandes, G.W. 2000. Variations in leaf characteristics of two species of Miconia in the Brazilian cerrado under the different light intensities. Tropical Ecology 41(1): 47-60.

Mediavilla, S.; Escudero, A. \& Heilmeier, H. 2001. Internal leaf anatomy and photosynthetic resource-use efficiency: interspecific and intraspecific comparisons. Tree Physiology 21: 251-259.

Medina, E.; Garcia, V. \& Cuevas, E. 1990. Sclerophylly and oligotrophic environments: relationships between leaf structure, mineral nutrient content, and drought resistance in Tropical Rain Forests of the upper Rio Negro region. Biotropica 22(1): 51-64.

Meirelles, M.L.; Oliveira, R.C.; Vivaldi, L.J.; Reatto, A. \& Correa, J.R. 2002. Espécies do estrato herbáceo e a altura do lençol freático em áreas úmidas do Cerrado (Planaltina, DF). Planaltina, Embrapa Cerrados.

Meirelles, M.L., Guimarães, A.J.M., Oliveira, R.C., Araújo, G.M. \& Ribeiro, J.F. 2004. Impactos sobre o estrato herbáceo de Áreas Úmidas do Cerrado. In: Aguiar, L.M.S. \& Camargo, A.J.A. (Orgs.) Cerrado: ecologia e caracterização. Planaltina. Embrapa Cerrados.

Mentink, H. \& Baas, P. 1992. Leaf anatomy of the Melastomataceae, Memecylaceae and Crypteroniaceae. Blumea 37(1): 189-225.

Metcalfe, C.R. \& Chalk, L. 1979. Anatomy of the dicotyledons: systematic antomy of the leaf and stem. v.1. Oxford, Clarendon Press.

Milanez, C.R.D. 2007. Estudos anatômicos e ultra-estruturais em Melastomataceae de Cerrado. Tese de Doutorado. Universidade Estadual Paulista Júlio de Mesquita Filho, Botucatu.

Milanez, C.R.D. \& Machado, S.R. 2007. Leaf emergences in Microlepsis oleaefolia (DC.) Triana (Melastomataceae) and their probable function: an anatomical and ultrastructural study. Micron 39(7): 884-890.

Oliveira, G.C. 2005. Perfil florístico e distribuição das espécies vegetais, em relação ao gradiente de umidade do solo, em seis veredas no Triângulo Mineiro. Dissertação de Mestrado, Universidade Federal de Uberlândia, Uberlândia.

Oliveira, J.B.S. 2007. Anatomia foliar como subsídio à taxonomia de Miconia Ruiz et Pav. (Melastomataceae) em Pernambuco - Brasil. Dissertação de Mestrado, Universidade Federal Rural de Pernambuco, Recife.

Paiva, J.G.A.; Fank-De-Carvalho, S.M.; Magalhães, M.P. \& GracianoRibeiro, D. 2006. Verniz vitral incolor 500: uma alternativa de meio de montagem economicamente viável. Acta Botanica Brasilica 20(2): 257-264.

Paviani, T.I. 1978. Anatomia vegetal e cerrado. Ciência e Cultura 30(9): 1076-1086.

Prychid, C.J. \& Rudall, P.J. 1999. Calcium oxalate crystals in monocotyledons: a review of their structure and systematic. Annals of Botany 84: 725-739.

Rao, T.A.; Bremer, K. \& Chakraborti, S. 1980. Foliar sclereids in Sri Lanka (Ceylonese) species of Memecylon (Melastomataceae). Botaniska Notiser 133(3): 397-401.

Read, J.; Sanson, G.D.; Garine-Wichatitsky, M. \& Jaffre, T. 2006. Sclerophylly in two contrasting tropical environments: low nutrients vs. low rainfall. American Journal of Botany 93(11): 1601-1614.

Reatto, A.; Correia, J.R. \& Spera, S.T. 1998. Solos do Bioma Cerrado: aspectos pedológicos. Pp.47-86. In: Sano, S.M. \& Almeida, S.P. (Orgs.). Cerrado: ambiente e flora. Planaltina, Embrapa - CPAC.

Reginato, M.; Boeger, M.R.T. \& Goldenberg, R. 2009. Comparative anatomy of the vegetative organs in Pleiochiton A. Gray (Melastomataceae), with emphasis on adaptations to epiphytism. Flora 204: 782-790.

Reis, C.; Proença, S.L. \& Sajo, M.G. 2004. Vascularização foliar e anatomia do pecíolo de Melastomataceae do cerrado do Estado de São Paulo, Brasil. Acta Botanica Brasilica 18(4): 987-999. 
Reis, C.; Bieras, A.C. \& Sajo, M.G. 2005. Anatomia foliar de Melastomataceae do Cerrado do estado de São Paulo. Revista Brasileira de Botânica 28(3): 451-466

Ribeiro, J.F.; Walter, B.M.T. 2008. As principais fitofisionomias do Bioma Cerrado. In: Sano, S.M.; Almeida, S.P. \&, Ribeiro, J.F. (Orgs.). Cerrado: ecologia e flora. v.1. Brasília, Embrapa Cerrados.

Ribeiro, S.P.; Corrêa, T.L. \& Sousa, H.C. 2010. Microscopic variability in mechanical defence and herbivory response in microphyllous leaves of tropical herb species from Serra do Cipó, Brazil. Revista Brasileira de Botânica 33(2): 237-246.

Rio, M.C.S.; Kinoshita, L.S. \& Castro, M.M. 2005. Anatomia foliar como subsídio para a taxonomia de espécies de Forsteronia G. Mey. (Apocynaceae) dos cerrados paulistas. Revista Brasileira de Botânica 28(4): 713-726.

Rôças, G.; Barros, C.F. \& Scarano, F.R. 1997. Leaf anatomy of Alchornea triplinervia (Euphorbiaceae) under distinct light regimes in a Brazilian montane Atlantic rain forest. Trees 11: 469-473.

Rossatto, D.R. \& Kolb, R.M. 2010. Gochnatia polymorpha (Less.) Cabrera (Asteraceae) changes in leaf structure due to differences in light and edaphic conditions. Acta Botanica Brasilica 24(3): 605-612.

Silva Júnior, M.C. \& Felfili, J.M. 1996. A vegetação da Estação Ecológica de Águas Emendadas. Brasília, Instituto de Ecologia e Meio Ambiente do Distrito Federal.

Sobrado, M.A. \& Medina, E. 1980. General morphology, anatomical structure, and nutrient content of sclerophyllous leaves of the 'bana' vegetation of Amazonas. Oecologia 45: 341-345.
Sousa, H.C. 1997. Estudo comparativo de adaptações anatômicas em órgãos vegetativos de espécies de Lavoisiera DC. (Melastomataceae) da Serra do Cipó, MG. Tese de Doutorado, Universidade de São Paulo, São Paulo.

Souza, W. 1998. Técnicas de microscopia eletrônica aplicadas às Ciências Biológicas. Rio de Janeiro, SBME.

Souza, R.C.S. \& Marquete, O. 2000. Miconia tristis Spring e Miconia doriana Cogn. (Melastomataceae): anatomia do eixo vegetativo e folhas. Rodriguésia 71(78/79): 133-142.

Strauss-Debenedetti, S. \& Berlyn, G.P. 1994. Leaf anatomical responses to light in five tropical Moraceae of different successional status. American Journal of Botany 81(12): 1582-1591.

Taiz, L. \& Zeiger, E. 2009. Fisiologia Vegetal. 4ed. Porto Alegre, Artmed Turner, I.M. 1994. Sclerophylly: primarily protective? Functional Ecology 8: 669-675.

Wang, W.; Xiao, Y.; Chen, L. \& Lin, P. 2007. Leaf anatomical responses to periodical waterlogging in simulated semidiurnal tides in mangrove Bruguiera gymnorrhiza seedlings. Aquatic Botany 86: $223-228$.

Wurdack, J.J. 1986. Atlas of hair for neotropical Melastomataceae. Smithsonian Contributions to Botany 63:1-80.

Zaman, S \& Padmesh, S. 2009. Leaf Anatomical Adaptations of Selected Kuwait's Native Desert Plants. European Journal of Scientific Research 2: 261-268.

Zar, J.H. 2009. Biostatistical analysis. 5ed. New Jersey, Pearson Prentice Hall. 